\title{
ERRATUM \\ Evidence for the distribution of perchlorates on Mars - ERRATUM
}

\author{
Benton C. Clark and Samuel P. Kounaves
}

doi:10.1017/S1473550415000385, Published by Cambridge University Press, $1^{\text {st }}$ October 2015.

We wish to advise readers of a publishing error for one of the articles intended for the forthcoming special issue on Astrobiological implications for Perchlorates on Mars. The article by Clark and Kounaves (2015), which was published online on $1^{\text {st }}$ October 2015 was inadvertently placed in Volume 15, issue 4. This article should have been placed alongside the other articles in the special issue. In order to preserve the intended composition of the special issue, the link here will redirect readers to the article in its published location. This was an error made by the Publisher, who apologises to the authors and readers.

\section{Reference}

Clark, B.C. \& Kounaves, S.P. (2015). Evidence for the distribution of perchlorates on Mars. Int. J. Astrobiol. 15, 311-318. 